\title{
California communities deal with conflict and adjustment at the urban-agricultural edge
}

by Alvin D. Sokolow, Sonja Varea Hammond, Maxwell Norton, and Evan E. Schmidt

About 2.5 million agricultural acres are located adjacent or in close proximity to nonfarm residences in California, leading to widespread farm-residential conflicts. This exploratory study compared high- and low-conflict edges in four crop-growing communities in two counties. (A separate analysis of San Diego County in a sidebar compares two edge situations involving animal and nursery operations.) We present tentative generalizations about conflict variations, sources and solutions. High conflict levels were largely due to residents' unfamiliarity with agricultural activities, although conflict levels were also related to specific farming practices. We also pose questions to guide further and more systematic research on the edge issue in California agriculture.

alifornia agriculture is substantially affected by ongoing urban growth. While sustaining the nation's largest agricultural economy, the state continues to add about 350,000 new residents each year. As well as converting farmland to nonagricultural uses, urbanization creates serious residentialfarm conflicts - the so-called "edge" problem (see box). In many agricultural areas, residential populations in close proximity impede the productivity, efficiency and profitability of farm operations.

California newspapers offer numerous accounts of edge issues in particular locales (Levin 2000; Morain 1991; Price 1994; Vellinga 2007; Sokolow 2003). The harm to agriculture includes limitations on routine practices such as chemical applications and cultivation, liability for trespassers, theft,

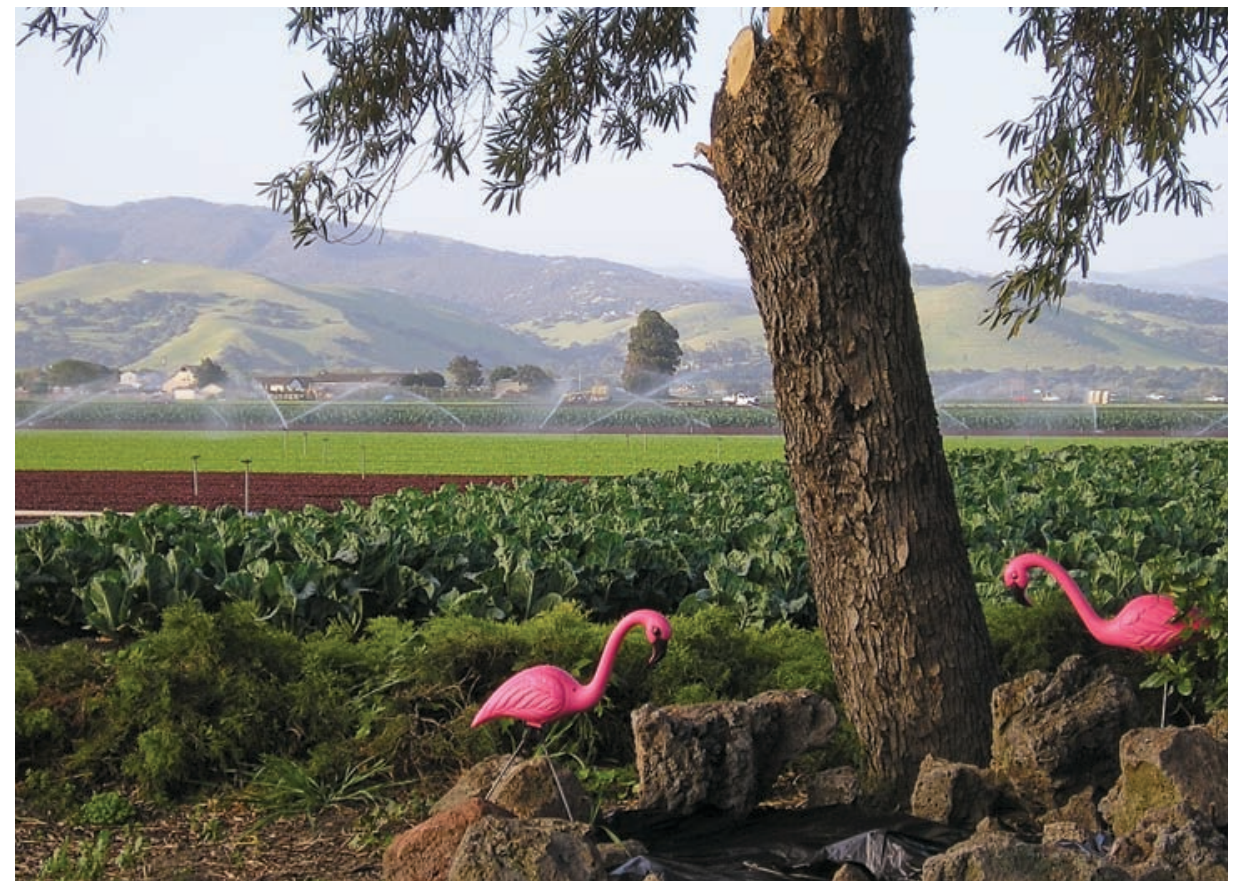

In California, an estimated 2.5 million agricultural acres are located within one-third mile of an urbanized area. Above, in south Salinas a landscaped driveway faces irrigated fields.

vandalism, imported pests and increased traffic on rural roads. Negative impacts also occur on the other side: Residential neighbors have problems with odors, noise, nighttime operations, dust, pesticide sprays and other nuisances, or even health problems associated with agricultural operations. The edge problem is not unique to California. It appears in many other parts of the nation where urbanization extends into commercial agricultural areas (Jackson-Smith and Sharp 2008; Abdalla and Kelsey 1996; Larson et al. 2001; Van Driesche et al. 1987).

These accounts are usually anecdotal or prescriptive in nature, lacking a systematic examination of the causes and effects of agricultural-residential conflicts, especially one that builds on a comparison of different edge situations. We present a comparative case analysis focusing on two alternative explanations for conflict variations: (1) the nature of specific commodities grown and (2) the characteristics of residential neighbors. This exploratory study was based on edge situations in
Conversions and edges: How much farmland is affected?

Close to 40,000 acres of agricultural land - a little more than one-tenth of $1 \%$ of California's total - are converted to urban uses annually (CDC 2006). Far more farm acres, however, are located in close proximity to residential neighbors. An estimated 2.5 million agricultural acres throughout California are within one-third mile of urban edges (Sokolow 2003). In 2004, this estimate was updated based on a calculation in that year of 12,137 edge miles statewide where agricultural land bordered residential and other urban land; cropland edges totaled 7,886 miles. These numbers actually underestimate the true extent of edges, since they are based on the state definition of "urban and built-up" land as six or more structures per 10 acres and do not account for separated, single residences in rural areas. 
two localities in each of two California counties with significant crop production.

\section{Research in sample communities}

From 2003 to 2005, we conducted open-ended interviews, in person and by phone, with county agricultural commissioners and their staffs, county government officials, agricultural leaders and individual farmers in Merced and Monterey counties, which are located in the Central Valley and Central Coast, respectively. Along with San Diego County on the southern coast (see sidebar, page 127), these farm counties rank among the top 10 in the state in agricultural income, each with more than $\$ 1$ billion in commodity sales annually. All have growing urban populations in their agricultural areas that suggest the potential for significant edge conflicts.

The sample counties were selected because they are the field locations of co-authors who are UC Cooperative Extension advisors. Thoroughly familiar with local agricultural conditions, the advisors also chose the persons interviewed, conducted some of the interviews and helped select the specific communities for study. For each of the two sample counties, we selected two communities to compare - one relatively "high" and the other relatively

\begin{tabular}{|c|c|c|c|c|}
\hline & \multicolumn{2}{|c|}{ Merced County } & \multicolumn{2}{|c|}{ Monterey County } \\
\hline & Los Banos & Livingston & Prunedale & Salinas \\
\hline Relative degree of edge conflict & High conflict & Low conflict & High conflict & Low conflict \\
\hline Type & City & City & Unincorporated & City \\
\hline Edge segment studied & $\begin{array}{l}\mathrm{N}, \mathrm{W}, \mathrm{S} \\
\text { borders }\end{array}$ & $S$ border & $\begin{array}{l}\text { Entire } \\
\text { community }\end{array}$ & SW border \\
\hline 2000 population & 25,869 & 10,473 & 16,432 & $151,060 *$ \\
\hline $\begin{array}{l}\text { Population increase entire } \\
\text { community, 1990-2000 (\%) }\end{array}$ & 72.8 & 43.1 & 122.2 & 38.8 \\
\hline Agricultural commodities produced & $\begin{array}{l}\text { Cattle, dairy, } \\
\text { forage crops }\end{array}$ & $\begin{array}{l}\text { Almonds, } \\
\text { peaches, } \\
\text { sweet } \\
\text { potatoes }\end{array}$ & $\begin{array}{l}\text { Strawberries, } \\
\text { cut flowers }\end{array}$ & $\begin{array}{l}\text { Vegetables, } \\
\text { strawberries, } \\
\text { animals }\end{array}$ \\
\hline
\end{tabular}

"low" in the degree of perceived conflict between farmers and residential neighbors (table 1).

Three of the communities are incorporated cities, governed by municipal governments; the fourth, Prunedale in Monterey County, is unincorporated and most of its local government services and regulations - including land-use planning - are provided by county government. There are notable differences among the four communities in size, recent population growth and principal agricultural commodities. Two San Diego County communities, the unincorporated area of Ramona and the city of Oceanside, are the subject of a separate analysis (see sidebar, page 127).

\section{Conflict variations and issues}

In distinguishing between high- and low-conflict situations among the four sample edges, we looked for evidence of the relative intensity of disagreements between farmers and residential neighbors. The indicators included: (1) the volume, variety and duration of perceived problems about agricultural practices raised in residents' complaints, as described by county officials and other interviewees and (2)

\begin{tabular}{|c|c|c|c|c|}
\hline & \multicolumn{2}{|c|}{ Merced County } & \multicolumn{2}{|c|}{ Monterey County } \\
\hline & Los Banos & Livingston & Prunedale & Salinas \\
\hline Relative degree of edge conflict & High conflict & Low conflict & High conflict & Low conflict \\
\hline $\begin{array}{l}\text { Problems perceived by residents, } \\
\text { approximate order of severity }\end{array}$ & $\begin{array}{l}\text { Airplane, helicopter noise } \\
\text { Defoliant smell } \\
\text { Air quality } \\
\text { Pests } \\
\text { Dust } \\
\text { Pesticide drift on vehicles }\end{array}$ & $\begin{array}{l}\text { Night agricultural work } \\
\text { Pesticide drift } \\
\text { Odor }\end{array}$ & $\begin{array}{l}\text { Drainage } \\
\text { Soil erosion } \\
\text { Fumigation } \\
\text { Pesticide drift } \\
\text { Animals and related noise or } \\
\text { illegal activity }\end{array}$ & Odor \\
\hline $\begin{array}{l}\text { Problems perceived by farmers, } \\
\text { approximate order of severity }\end{array}$ & $\begin{array}{l}\text { Trash on farms, roads } \\
\text { Trespassing } \\
\text { Theft } \\
\text { Vandalism } \\
\text { Operational restrictions }\end{array}$ & $\begin{array}{l}\text { Vandalism } \\
\text { Trespassing } \\
\text { Theft } \\
\text { Operational restrictions } \\
\text { Traffic congestion }\end{array}$ & $\begin{array}{l}\text { Theft } \\
\text { Drainage } \\
\text { Operational restrictions } \\
\text { Ranchettes } \\
\text { Competition for water } \\
\text { Dumping }\end{array}$ & None or minimal \\
\hline Persons interviewed & $\begin{array}{l}\text { Seven farmers } \\
\text { Two agricultural co } \\
\text { Three aerial pestici } \\
\text { Three city planners } \\
\text { Chamber of Comm }\end{array}$ & $\begin{array}{l}\text { issioner staff } \\
\text { ipplicators } \\
\text { official }\end{array}$ & $\begin{array}{l}\text { Four farmers } \\
\text { One agricultural com } \\
\text { Three staff of agricul } \\
\text { Four county governm } \\
\text { One aerial pesticide } \\
\text { Two agricultural cons }\end{array}$ & $\begin{array}{l}\text { nissioner staff } \\
\text { ural organizations } \\
\text { ent staff } \\
\text { oplicator } \\
\text { Itants }\end{array}$ \\
\hline
\end{tabular}


farmers' perceptions about the negative impacts of adjacent residents on their agricultural operations, as expressed in interviews.

Our data generally cover a 5-year period, starting in the late 1990s and concluding in about 2004. Edge-conflict patterns can fluctuate over time as farming practices and/or residential populations change, so the conflicts identified here are not necessarily longterm.

The study identified and compared high- and low-conflict segments within each of the two counties, rather than comparing them overall (table 2).

Merced County. The volume and variety of complaints by residents about nearby farm operations marked the Los Banos edge as much more conflictual than the Livingston edge in the late 1990s and early 2000s, according to two staff members of the Merced agricultural commissioner assigned to the Los Banos and Livingston field offices. They and other interviewees noted that residential complaints had greatly increased in recent years in Los Banos as a result of the city's rapid population growth and expansion into surrounding farmland (fig. 1). While we lack specific numbers, interviewees said that the list of residents' complaints was topped by noise from airplanes and helicopters spraying chemicals, the smell of defoliants and other chemicals applied to cotton fields, and poor air quality. In the late summer, people complained about respiratory problems attributed to the application of cotton defoliants and other farm practices.

In contrast, complaints from residential neighbors of farms around Livingston were relatively few and mild during the same period. Pesticiderelated objections were infrequent, according to one agricultural commissioner's staffer, not exceeding five per year. The top issue was noise and dust from the blast sprayers used to spread pesticides on orchard treetops.

On the agricultural side of the edge, problems were generally similar around the two cities, and included trespassing, theft, vandalism and restrictions on farming practices (table 2). Farmers in Los Banos regarded edge issues as more serious than in Livingston. Theft and trash dumped on farmland and local roads were cited as a bigger problem for agriculture in the Los Banos area than around Livingston.

Monterey County. The consensus among Monterey County interviewees was that edge problems were more pronounced in unincorporated Prunedale in northern Monterey County than on the southern border of the city of Salinas (fig. 2). With single rural home sites interspersed among small strawberry, flower and other farms, there were ample opportunities for edge conflicts in Prunedale. The most serious problems expressed by residents in the early 2000s concerned soil erosion, poor drainage of runoff water, and the smell and health hazards of fumigating strawberry fields with methyl bromide. A small group of residential opponents to agricultural practices in the north county had organized as the "Code Rangers." They monitored local conditions and reported perceived violations of county codes to county officials. One target was erosion created by strawberry fields.

In comparison, the agricultural area on the southern edge of Salinas, a relatively stable locale with little population growth since the 1970s and with more distinct farm-residential borders, was relatively problem free. In fact, interviewees could not recall any substantial complaints from residential neighbors in recent years, with the exception of some protests about odors.

Problems perceived by farmers paralleled the residents' complaint pattern, with no issues recorded for south Salinas. Some of the same problems - drainage, erosion and

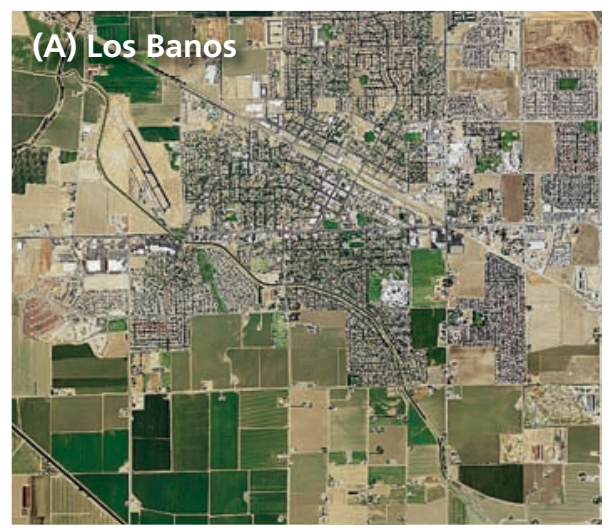

Fig. 1. Aerial photo comparisons of (A) Los Banos and (B) Livingston in Merced County in 2009 suggest that urban-agricultural borders were more irregular around Los Banos than around Livingston, possibly helping to generate higher levels of edge conflict in Los Banos.

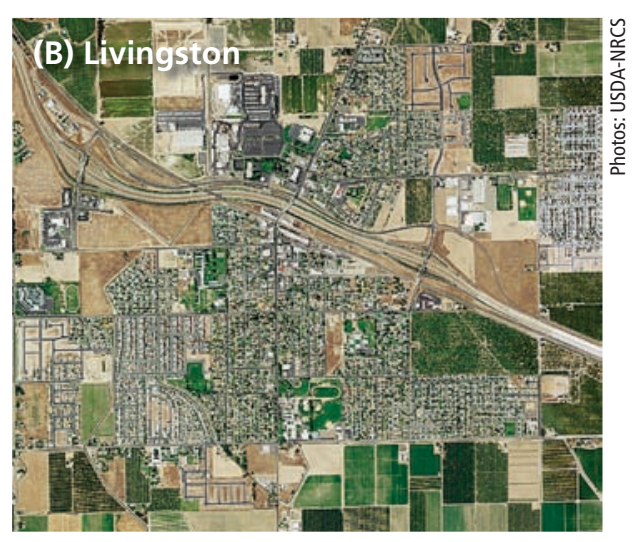

fumigation - that were the basis of residents' complaints also bothered farmers, although from a different perspective. Runoff problems were seen by farmers in Prunedale as partially caused by home and road construction, and fumigation restrictions led to increased costs and operational adjustments for strawberry growers. Theft also was a major problem, as one farmer reported: "We had a truck parked on the ranch and they actually stole the radiator and the four-wheel-drive mechanism ... We had trailers broken into, probably about a thousand dollars of small tools lost. We keep nothing out there anymore, not even a shovel. That's the hardest part about farming in north Monterey County now. I know that everybody who farms in the area has had that problem" (phone interview, Jan. 28, 2005).

\section{Commodity production and practices}

What accounts for the variations in edge conflicts from place to place?$$
\text { . }
$$ 
(A) Prunedale

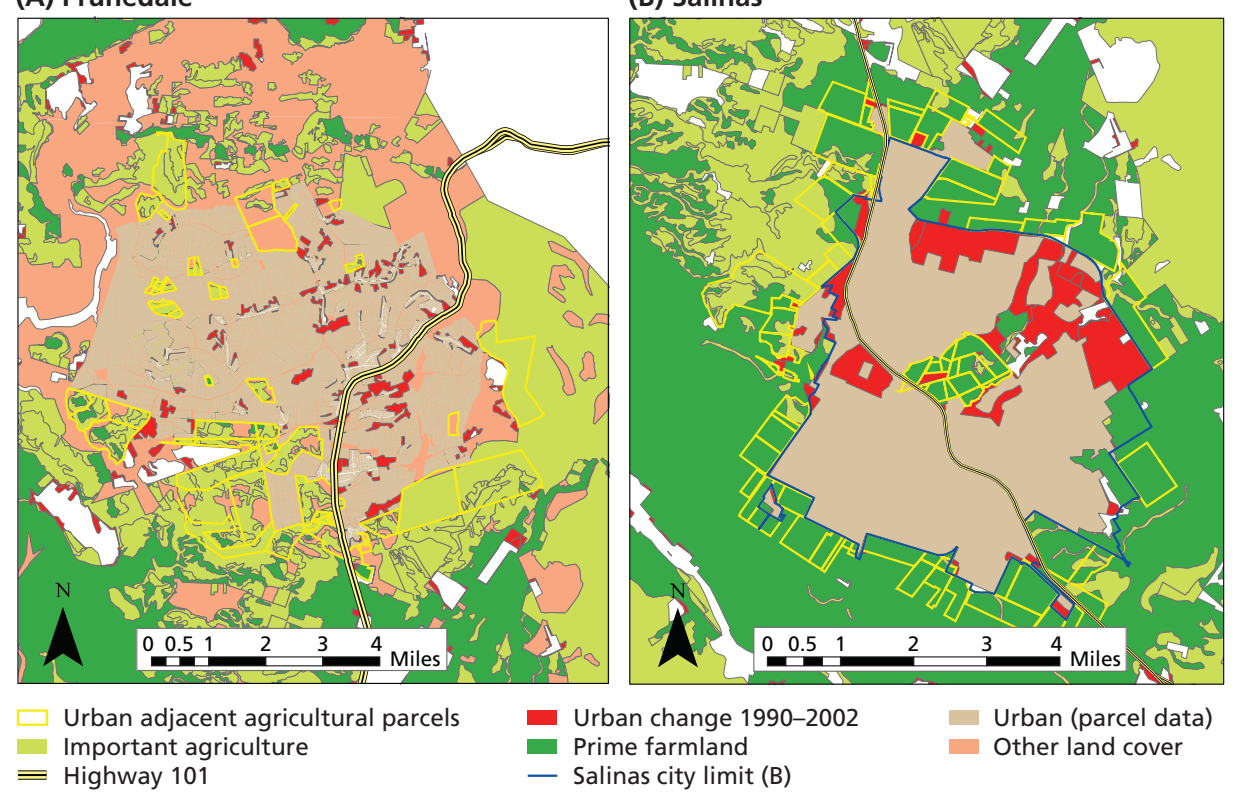

Fig. 2. The GIS-mapped relationship of urban and agricultural parcels in Monterey County in 2002 shows a fragmented pattern in (A) unincorporated Prunedale as compared to the relatively straight line on the southern edge of (B) the city of Salinas. Urban-agricultural conflicts were much more intense in the latter than the former area in the late 1990s and early 2000s. Source: Nathaniel Roth, Information Center for the Environment, UC Davis, based on information from Monterey County and the California Department of Conservation Farmland Mapping and Monitoring Program.

The case studies suggest two contrasting explanations, one concerning the nature of agricultural practices and the other related to the degree that edge residents are newcomers with urban backgrounds. On the one hand, more intense conflicts at the edge can be attributed to specific farming activities that generate extensive negative impacts (Connell 1999; Levin 2000; Vellinga 2007). On the other hand, new residents who are unfamiliar with country life and agriculture may have relatively little tolerance for farm operations (Morain 1991; Leavenworth 2000). These explanations have been separately identified in newspaper accounts and academic research, but without comparing the two factors.

Virtually all agricultural operations have the potential to disturb nearby residents. But the potential may be

\section{Farmers and ranchers have}

\section{some ability to increase}

or reduce edge problems, depending on how they operate. greater for certain kinds of farm commodities - such as crops that require heavy applications of pesticides or other chemicals, or that involve intensive cultivation and harvesting that generate dust, noise and nighttime impacts. Confined-animal facilities such as dairies, poultry ranches and hog farms are especially conducive to negative impacts, largely because of their waste products (Baca 2002; Castle 1998; Henderson 1998; Hirschl and Long 1993; Schwab 1998; Turner 2003) (see sidebar, page 127).

Some of these crop conditions were present in our study's four edge segments, but were more pronounced in the high-conflict than the low-conflict edges, as seen with concern about the smell of defoliants used in cotton production around Los Banos (Merced County) and the use of methyl bromide on strawberry fields in Prunedale (Monterey County).

The issue may not be about the particular commodity grown, as some interviewees suggested, but rather how it is grown - including management practices such as pesticide applications, the timing of noisy harvest activities and equipment maintenance. Farmers and ranchers have some ability to increase or reduce edge problems, depending on how they operate.

\section{New residents from urban areas}

People who occupy homes adjacent to agricultural operations vary in their tolerance of farming practices. The conventional wisdom repeated in newspaper reports is that newly arrived edge residents with urban backgrounds are more likely to be upset by local farm operations than residents with rural backgrounds and longer tenure in a locality. Our research supports this observation. Indeed, differences in background characteristics and the duration of local residence offered the strongest explanation for the conflict variations in the two study counties.

Los Banos-Livingston. The most solid evidence came from the Los BanosLivingston comparison in Merced County. Both cities have traditional agriculture-dependent economies, and both have experienced substantial population increases since the 1980s. But the extent and character of this growth differed in major ways. The population of Los Banos (the high-conflict community) more than doubled from 1990 through 2004, from 14,519 to 30,650 residents. Growth in Livingston (the lowconflict community) was more modest, with a $59.9 \%$ increase, from 7,317 to 11,700 residents, during the same time.

The origins of growth differed significantly. In Los Banos, it stemmed mostly from the more urban Santa Clara County/San Jose area and other parts of the Bay Area. In Livingston, it was mostly from other areas of the relatively rural San Joaquin Valley.

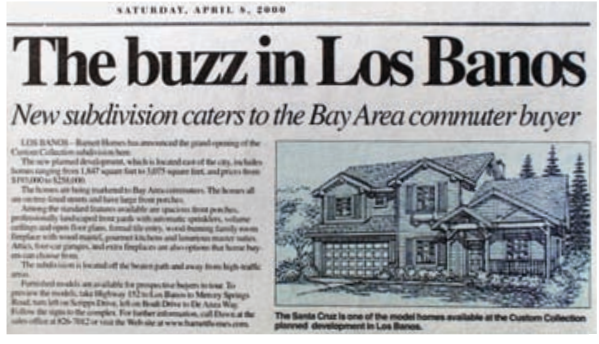

A newspaper article describes the conflicts that can arise when commuters purchase homes in primarily rural communities such as Los Banos, located about 60 miles from employment centers in the South Bay and East Bay. 
Los Banos is located on the west side of Merced County near Interstate 5, about 60 miles from major employment centers in the South Bay and East Bay, making it a long but manageable commute for urbanites seeking relatively inexpensive housing and small-town ambience. The result has been the development of a newcomer/old-timer divide in Los Banos. Newer residents have higher incomes, are residentially concentrated in new subdivisions on the edge of town and adjacent to farms, and are more likely to work in occupations not associated with agriculture. Livingston, by contrast, is in the central part of the county, closer to other San Joaquin Valley communities and less accessible to Bay Area commuters. Its newer residents are more similar to their longer-term neighbors, and Livingston seems to lack the social and occupational divisions that have developed in Los Banos.

A staff member of the agricultural commissioner's office said: "New residents in the Los Banos area are not originally from the valley and have a very low tolerance to ag practices and consider them threatening. New residents in the valley communities grew up in the valley and they are accustomed to ag practices ... Bay Area people are very confrontational compared to those who grew up here. They like to carry complaints on up the chain of command" (phone interview, Sept. 20, 2004).

A comparison of U.S. Census data supports these perceived differences between Los Banos and Livingston (table 3): (1) between 1995 and 2000, proportionately more Los Banos residents had moved there from another county; (2) Los Banos residents had longer commutes to jobs in 2000; (3) there was a sharp decrease in the proportion of Los Banos workers employed in agriculture in 2000; and (4) Los Banos had higher income levels and faster income growth (median household income) in 19902000 than Livingston.

Prunedale-Salinas. Similar differences help explain the conflict variations between the two Monterey County edge segments. Prunedale, the high-conflict unincorporated community, experienced a population increase from 1990 to 2000 of $122 \%$, from 7,393 to 16,432 residents. The southern border of Salinas, the low-conflict edge, has been relatively stable in recent decades, with the last appreciable residential development occurring in the 1970s. In part because of proximity to good agricultural soils south and west of Salinas, city policy has limited further residential expansion in this area in favor of extending urban development to the north and east. All of Salinas had only a $39 \%$ population increase in the 1990 s, much smaller than Prunedale. Several interviewees pointed to the role of new residents in escalating the levels of perceived agriculture-related problems in Prunedale. One farmer noted: "The problem we have is that ... people who move to rural areas but who are basically from the city don't understand that water flows downhill. They also complain about dust. But everybody else is used to living down there, and they don't create problems" (phone interview, Jan. 28, 2005).

In 2000, larger percentages of Prunedale than Salinas residents reported: (1) living in other counties 5 years earlier; (2) workplace locations

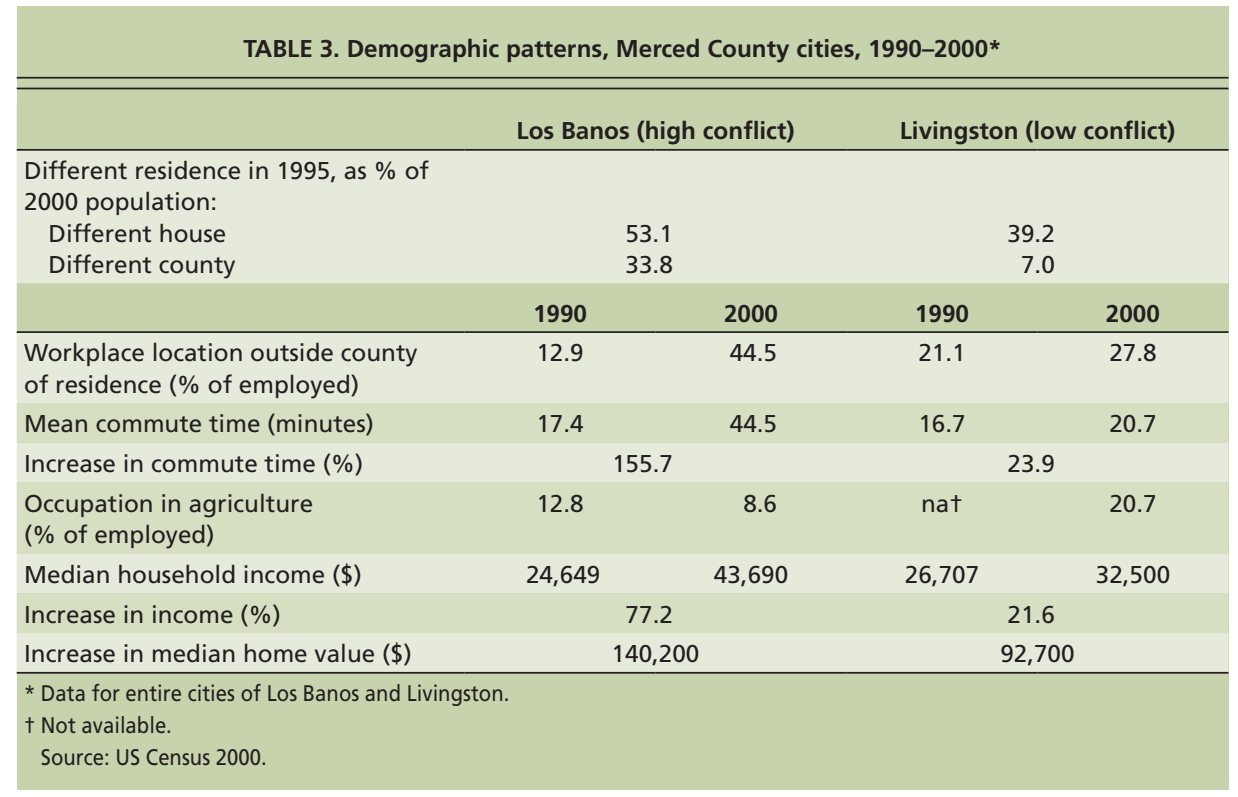

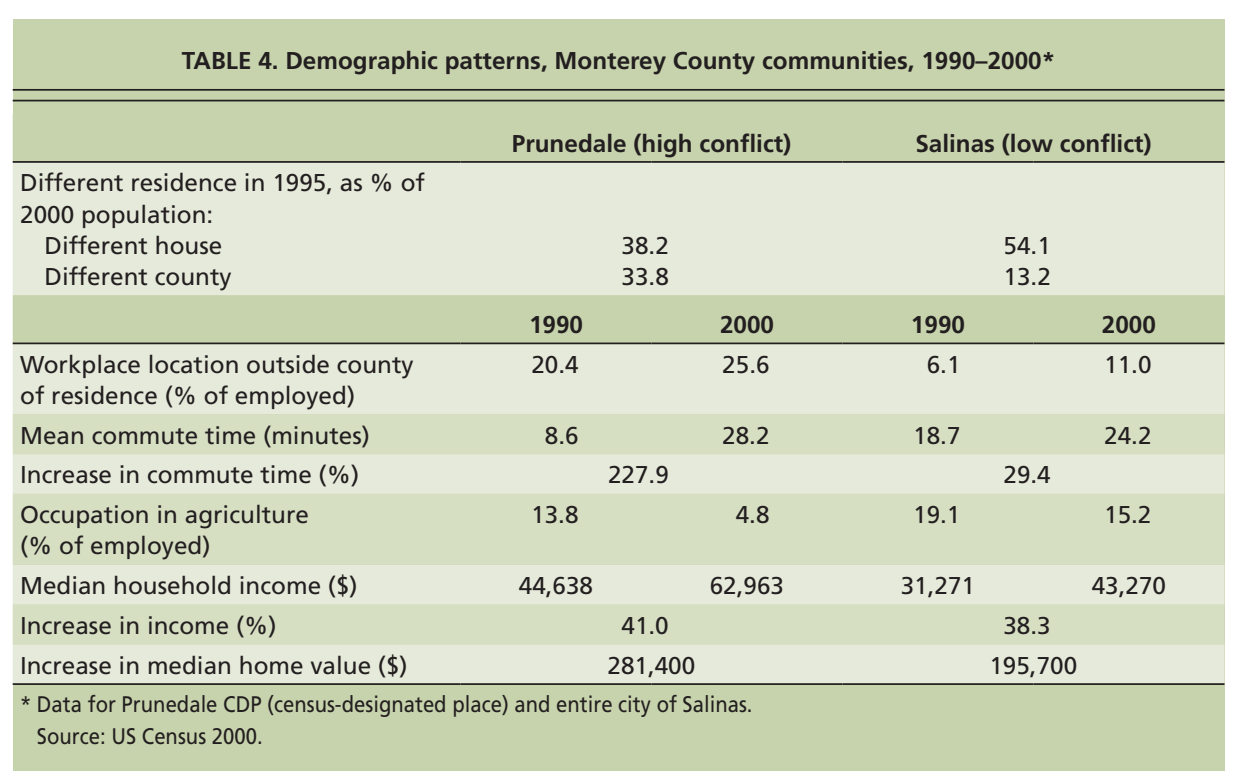


in other counties; and (3) employment in nonagricultural industries, with a sharp decrease in farm employment from 1990 to 2000 (table 4). Prunedale residents also had longer commutes to work, with a steep increase in mean commute times within the decade.

\section{Adjustments to avoid conflicts}

As others have suggested, the most effective efforts to limit the scope and incidence of conflict with residential neighbors may be farmer adjustments to their normal agricultural practices (Coppock and Kreith 1997).

Regulations. Adjustments in California are largely due to county government regulation on the farm use of pesticides and other health-related chemicals. The restrictions originate in state health protection laws administered by county agricultural commissioners. County environmental health and county or regional air-quality programs also regulate local agricultural practices. As noted by Merced County agricultural commissioner's staff, pesticide use close to residences is more closely monitored than applications elsewhere. Depending on the hazard level of the chemicals employed and particular edge configurations, farmers are sometimes required to use buffers of varying widths between houses and the fields where pesticides are applied.

Voluntary actions. Agricultural operators also engage in voluntary adjustments intended to head off potential problems. Interviewees described such "good neighbor" actions as:

- Notifying nearby residents of upcoming operations with the potential to generate substantial noise, dust or other annoyances.

- Conducting dusty or noisy field operations on days and at times when the fewest number of neighbors are likely to be affected.

- Operating harvest equipment to minimize dust spray.

- Installing decorative fences and landscaping buffers.

- Sharing produce with neighbors.

Aerial applications of pesticides onto fields and orchards are especially

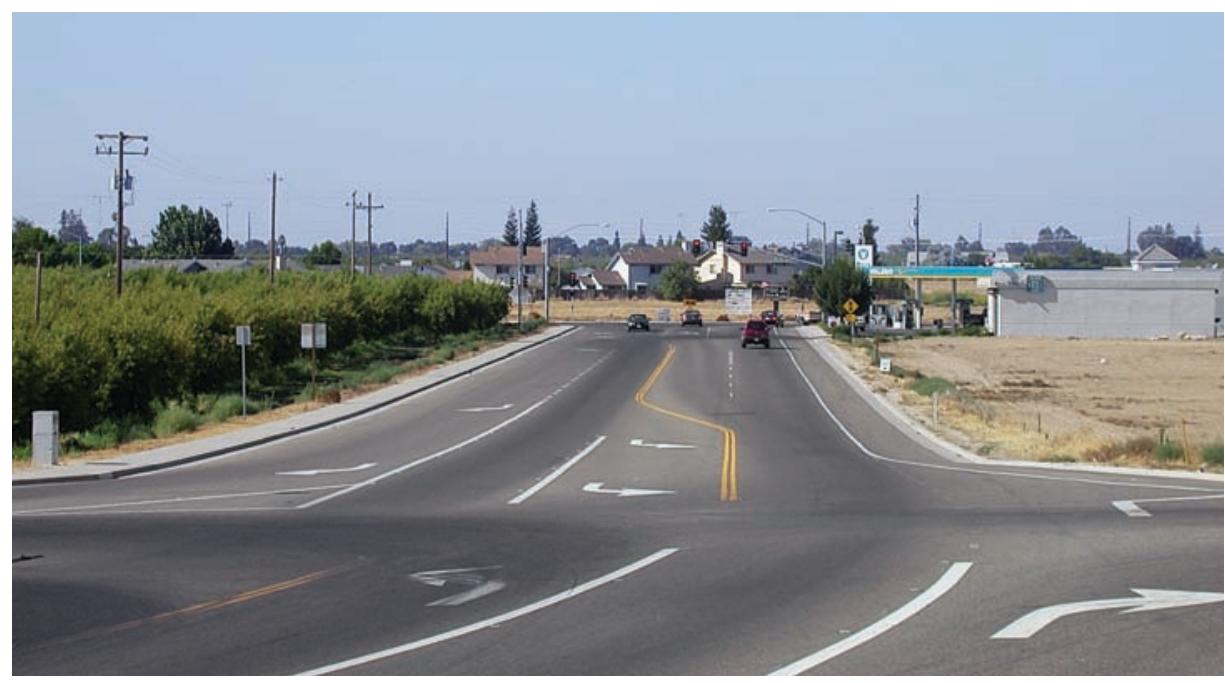

As population expands into agricultural areas, growers may complain about theft, vandalism and restrictions on farming practices. Such concerns were generally less common in Livingston, above.

vulnerable to residential edge problems. The four aerial applicators we interviewed who worked in Merced and/or Monterey counties described modifications to their operations in recent years due to residential development in agricultural areas. While such technological advances as quieter aircraft and GPS (global positioning systems) as a substitute for ground-flagging could be the inevitable progress of an industry seeking more efficiency, they appeared to be hastened by the need to improve the precision of spray applications in problematic areas. The applicators reported that they turned down jobs where edge configurations posed liability concerns; they also noted that about half of the aerial applicators in California had gone out of business or consolidated in recent years. One applicator who works in Merced County said: "Small (agricultural) parcels created by lot splits are more difficult and expensive to treat and also present more opportunities for off-site drift problems . . . Liability insurance costs are skyrocketing. When they hear a plane nearby, people just assume they are being poisoned. We receive lots of noise complaints" (phone interview, October 2004).

Neighbor adjustments. Generally seen as the victims of harmful agricultural practices, residents can also be the perpetuators of problems experienced by some farm operators, such as theft, vandalism and trespassing. However, we found no direct evidence of efforts by edge residents to avoid such impacts and respect agricultural property, since this was not a focus of the research and no interviews were conducted with residents. It is possible that individual adjustments may occur with, for example, families restraining unruly youngsters and controlling their dogs. Still, the incentives for adjustments by residents are far less obvious and compelling than the economic and regulatory factors that cause farm operators in edge locations to be careful about their production practices and protect their assets.

\section{Public policies and programs}

California local governments have considerable regulatory and other powers to limit or even prevent edge conflicts (Sokolow 2003). Perhaps the most effective are planning and zoning actions that determine the location and configuration of new residential developments (Handel 1994). Available policies range from overall strategies, such as county-city agreements to divert new growth away from agricultural areas by concentrating it in cities (see page 129), to more specific requirements such as buffers and large minimum parcel sizes in agricultural zones. Nonregulatory measures, such as right-to-farm ordinances and educational programs, are generally regarded as less effective because of their voluntary and general nature (Wacker et al. 2001).

We have no evidence that such policy measures helped to control or (continued on page 128) 


\section{Confined facilities create conflicts in San Diego County communities}

by Alvin D. Sokolow, Ramiro E. Lobo and Kristen Hukari

$E^{c}$ dge conflicts often concern agricultural production methods that are different than the typical open fieldcrop operations found, for example, in Merced and Monterey counties. In particular, confined-animal production facilities can adversely affect residential neighbors, as recent events in the San Diego County communities of Ramona and Oceanside illustrate. The conflict associated with two poultry ranches in Ramona was relatively severe, as marked by its longevity, persistence of formal neighbor opposition and local government regulatory activity. Issues concerning a plant nursery in Oceanside were mild by comparison.

Ramona poultry farms. Twenty-five miles northeast of San Diego, Ramona is an unincorporated community that has lived with the odors and other impacts of major turkey and chicken facilities for most of a century. But residents' complaints starting in 2000 about two particular egg ranches, introduced a new level of agricultural-residential conflict. Criticism focused on health and air-quality problems, and odors and flies emanating from the two egg ranches, part of 10 such facilities in San Diego County owned by a family that had been in the poultry business for three generations. The two ranches were relatively older facilities, and some interviewees attributed the problems to a lapse in ranch management related to the recent death of the father of the family and a shift in control to two young brothers.

Nearby residents protested to the county supervisor, who became personally involved in the issue, as well as to the San Diego County Department of Environmental Health (DEH) and other agencies. Residential neighbors filed numerous complaints between 2000 and 2002, including four during a 3-day period in May 2002. At the same time, the two ranches came under increasing scrutiny from DEH staff, who reported excessive fly populations resulting from accumulated manure piles during regular inspections, and who issued violation notices in 2000 and 2001. In May 2001, the ranch owners and managers were ordered to appear before the county's Fly Abatement Appeals Board (FAAB) for failure to correct the problem. Twenty-five residents attended the hearing, which produced an order to abate the fly-breeding hazard and required manure-management procedures. After a second FAAB hearing in August 2001, the county filed a civil action in Superior Court against the owners, seeking penalties and injunctive relief for violations of county codes and the creation of a public nuisance.

A settlement agreement in November 2001 called for certain manure disposal and sanitary measures and a $\$ 25,000$ civil penalty. However, the neighbors' complaints continued, and the supervisor met several times with area constituents. In June and July 2002, the two parcels were sold to nonfarmers and ranch operations ceased.

Oceanside nursery. In this coastal city 30 miles north of San Diego, the involvement of residential neighbors in edge issues was relatively subdued and limited. Shortly after a large flower nursery was established in the Morro Hills area in 1998, neighbors began to complain to the greenhouse operator about noise, truck traffic, late hours, outdoor lights, litter and other problems.

The conflict eventually led to the revision of Oceanside's zoning ordinance in summer 2000, which (1) distinguished between open ground agriculture and operations in structures, (2) specified where nursery activities could be located on a farm site and (3) established new development standards. Fearing more burdensome restrictions than had been proposed, growers joined in the negotiations with homeowners and city planning staff that led to the new policy.

The conflict was constrained by city and county procedures. Oceanside deliberately supports commercial farming, particularly in designating an agricultural district - which includes South Morro Hills — where large-scale agriculture is encouraged and only low-density housing is permitted. San Diego County also has a mechanism intended to moderate edge problems, the Agricultural Interface Board. In early 2000, some of the parties involved requested that the agricultural commissioner convene the board, which is composed of technical experts, to mediate the greenhouse conflict. This effort was not successful.

Urbanization conflicts. How do these events compare with edge conflicts in in the four Central Valley communities (see page 121)? Unlike Merced and Monterey counties, the urban orientations of new residents were not noticeable factors in the development of conflicts. Newcomers were not prominent among the residential neighbors who complained about the egg ranches and nursery operation. The edge conflicts in Ramona and Oceanside resulted from commodity production and facility management issues.

The second important difference is that the two San Diego County com-

\section{The edge conflicts in Ramona and Oceanside resulted entirely from commodity production and facility management issues.}

munities made substantial use of local government policies and mechanisms that were largely absent in Merced and Monterey counties. County government regulatory agencies were actively involved in both the Ramona and Oceanside situations, and Oceanside's agriculture-friendly policies that seek to protect farming as a desirable long-term land use helped to limit the conflict. Indeed, San Diego County and the city of Oceanside are exceptional in this regard, because few other California local governments have comparable programs for dealing with agriculturalresidential conflicts.

A.D. Sokolow is Cooperative Extension Public Policy Specialist Emeritus, Department of Human and Community Development, UC Davis; R.E. Lobo is Farm Advisor, UC Cooperative Extension (UCCE), San Diego County; and K. Hukari was Program Representative, UCCE San Diego County. 
(continued from page 126)

limit edge conflicts in the four sample communities. While some complaints from residential neighbors were submitted to county agencies, there is no indication from interviewees or other sources that they led to specific regulatory or other governmental actions. However, county governments were prominent in edge conflicts in two

\section{What dollar amounts can be assigned to the costs of farming in edge locations?}

San Diego County communities (see sidebar, page 127), showing how public policies and their implementation can influence the incidence and intensity of edge conflicts.

\section{Further questions}

Several conclusions about the patterns of edge conflict in six communities in three counties (Merced, Monterey and San Diego) emerge from this exploratory study. Conflicts varied considerably by community or edge segment. Two factors explain conflict variations in particular cases: (1) the perceptions and backgrounds of residential neighbors and (2) farming practices. The most frequent and effective efforts to limit the scope and incidence of edge problems in the sample communities were farmers' adjustments either mandated or voluntary - in their agricultural practices, at some cost to their bottom lines.

Considering the small sample size and the exploratory nature of this study, these are tentative conclusions or informed hypotheses. They lead us to the following list of questions for more systematic research that would require larger samples of communities and interviewees, including residential neighbors:

(1) What do residential neighbors in edge locations say about the impacts of nearby agricultural operations, and how do these perceptions compare to those of neighboring farmers?

(2) When, how and to whom do residential neighbors express their complaints about agricultural operations? Do organized and individual forms of opposition achieve different results?
(3) What dollar amounts can be assigned to the costs of farming in edge locations, in lessened efficiency, productivity and profitability?

(4) Do conflicts at particular edges lessen over time, as these areas become more stable and former newcomers become settled old-timers?

(5) How do spatial patterns - residential locations in relation to agricultural activity as revealed by geographic information system (GIS) mapping affect the extent of edge conflicts?

(6) Finally, what is the relative effectiveness of various public policy measures - such as grievance procedures, right-to-farm ordinances, required buffers for new development and zoning in avoiding or reducing edge conflicts?

\section{A.D. Sokolow is Cooperative Extension Public} Policy Specialist Emeritus, Department of Human and Community Development, UC Davis; S. Varea Hammond is County Director, UC Cooperative Extension (UCCE), Monterey County; M. Norton is Farm Advisor, UCCE Merced County; and E.E. Schmidt is Recent Graduate, Geography Graduate Group, UC Davis. Portions of the research were supported by work group funds provided by the UC Division of Agriculture and Natural Resources.

\section{References}

Abdalla C, Kelsey T. 1996. Breaking the impasse: Helping communities cope with change at the rural-urban interface. J Soil Water Conserv 51:462-6.

Baca K. 2002. Big dairies, big fights. Sacramento Bee, Nov. 16

Castle E. 1998. Agricultural Industrialization in the American Countryside. Henry A. Wallace Institute for American Agriculture. Policy Studies Report No. 11. Greenbelt, MD. 45 p.

[CDC] California Department of Conservation. 2006 California Farmland Conversion Report, 2002-2004. Sacramento, CA.

Connell SA. 1999. A blossoming dispute over greenhouses. Los Angeles Times, April 11

Coppock R, Kreith M (eds). 1996. Farmers and Neighbors: Land Use, Pesticides, and Other Issues. UC Agricultural Issues Center, Davis, CA. 72 p

Coppock R, Kreith M (eds.). 1997. California's Future: Maintaining Viable Agriculture at the Urban Edge. UC Agricultural Issues Center, Davis, CA. 80 p.

Handel M. 1994. Conflicts and Solutions When Agricultural Land Meets Urban Development. M.S. thesis, Community Development, UC Davis. 122 p.
Henderson H. 1998. Noxious neighbors. Planning 63(10):4-9.

Hirschl TA, Long C. 1993. Dairy farm survival in a metropolitan area: Dutchess County, New York, 1984 1990. Rural Sociol 58(3):461-74.

Jackson-Smith D, Sharp J. 2008. Farming in the urban shadow: Supporting agriculture at the rural-urban interface. Rural Realities 2(4). Rural Sociological Society, Columbia, MO

Larson JM, Findeis JL, Smith SM. 2001. Agricultural adaptation to urbanization in southeastern Pennsylvania. ARE Rev 30(1):32-43.

Leavenworth S. 2000. Beef with neighbor mars her bucolic lifestyle. Sacramento Bee, Feb. 5 .

Levin C. 2000. Pesticides: The price of living by farms. Ventura County Star, Dec. 10

Morain D. 1991. Cultures clashing down on the farm. Los Angeles Times, Oct. 6.

Price R. 1994. Do farmers till the land or reap its value? Bakersfield Californian, Oct. 23.

Schwab J. 1998. Planning and Zoning for Concentrated Animal Feeding Operations. American Planning Association, Planning Advisory Service Rep 482. Chicago, IL.
Sokolow AD. 2003. California's edge problem: Urban impacts on agriculture. In: Siebert J (ed.). California Agriculture: Dimensions and Issues. UC Giannini Foundation of Agricultural Economics, Davis, CA. Information Series 03-1. p 289-304.

Turner M. 2003. Supervisors give ok for hog farm to stay. Modesto Bee, July 9.

US Census. 2002. US Census of Population and Housing; Summary of Social, Economic and Housing Characteristics, 2000. Washington, DC.

Van Driesche RG, Carlson J, Ferro DN, Clark JM. 1987 Pesticides and suburban agriculture. In: Lockeretz W (ed.). Sustaining Agriculture Near Cities. Soil and Water Conservation Society, Ankeny, IA.

Varea Hammond S. 2002. Can city and farm coexist? The agricultural buffer experience in California. Great Valley Center, Modesto, CA. 26 p.

Vellinga ML. 2007. Grappling with vintners' growth. Sacramento Bee, Nov. 6.

Wacker M, Sokolow A, Elkins R. 2001. County rightto-farm ordinances in California: An assessment of impact and effectiveness. AIC Issues Brief 15. UC Agricultural Issues Center, Davis, CA. 8 p. 